\title{
OS DESAFIOS NO ENSINO DE MATEMÁTICA PARA UMA ALUNA COM DEFICIÊNCIA VISUAL EM UMA ESCOLA INCLUSIVA
}

\section{CHALLENGES IN MATH TEACHING FOR A VISUALLY DISABLED STUDENT IN AN INCLUSIVE SCHOOL}

Jorge de Menezes Rodrigues ${ }^{1}$

ORCID iD: $\underline{0000-0002-2200-7559}$

Elielson Ribeiro de Sales ${ }^{2}$

ORCID iD: $\underline{0000-0001-6242-582 X}$

\section{RESUMO}

O presente artigo tem como objetivo analisar o processo de ensino e aprendizagem em matemática, perante as dificuldades encontradas por uma aluna com deficiência visual a partir das práticas metodológicas inseridas por uma professora de matemática. Participaram da pesquisa uma aluna com deficiência visual e uma professora de matemática. A pesquisa foi realizada durante as aulas de matemática em uma turma do $6^{\circ}$ ano B na cidade de Manaus, tendo uma abordagem qualitativa. Para a coleta de dados aplicamos como técnica de pesquisa a entrevista semiestruturada para ambos os participantes e observação participante na qual elaboramos um roteiro para identificarmos pontos essenciais relacionados às possíveis barreiras encontradas durante o processo de ensino e aprendizagem da professora e aluna cega durante as aulas de matemática. Os resultados obtidos pela pesquisa apontaram algumas situações vivenciadas no processo de inclusão como as dificuldades da educadora ensinar uma pessoa com deficiência visual, além de mostrar algumas barreiras pedagógicas existentes para uma discente cega nas aulas de matemática, além da importância da construção e uso de materiais didáticos de acessibilidade a serem aplicadas nas aulas de matemática direcionados as pessoas com necessidades educacionais especiais.

Palavras-chave: Inclusão. Deficiência Visual. Ensino de Matemática.

\begin{abstract}
This article aims to analyze the process of teaching and learning in mathematics, given the difficulties encountered by a student with visual impairment from the methodological practices inserted by a math teacher. One student with visual impairment and a math teacher participated in the research. The research was conducted during math classes in a 6th grade B class in Manaus city with a qualitative approach. For data collection we applied as a research technique a semi-structured interview for both participants and participant observation in which we developed a script to identify essential points related to possible barriers encountered during the teaching and learning process of the teacher and blind student during the classes. mathematics. The results obtained by the research point to some situations experienced in the inclusion process, such as the educator's difficulties in teaching a blind student, besides showing some existing pedagogical barriers for a visually impaired person in math classes, besides the importance of building and using materials. accessibility courses to be applied in math classes, aimed at people with special educational needs.
\end{abstract}

Keywords: Inclusion. Visual impairment. Math teaching.

\footnotetext{
${ }^{1}$ Doutor em Educação em Ciências e Matemática pela Universidade Federal de Mato Grosso (UFMT). Professor da Universidade do Estado do Amazonas (UEA), Manaus, Amazonas, Brasil. Avenida Djalma Batista, 2470, Chapada, Manaus/AM/Brasil, CEP: 69050-300 E-mail: jdmrodrigues@uea.edu.br.

${ }^{2}$ Doutor em Educação Matemática pela Universidade Estadual Paulista "Júlio de Mesquita Filho" (UNESP). Professor da Universidade Federal do Pará (UFPA), Belém, Pará, Brasil. Avenida Augusto Corrêa, 1, IEMCI/UFPA, Sala 221, Guamá, Belém/PA/Brasil, CEP: 66075-110. E-mail: esales@ufpa.br.
} 


\section{INTRODUÇÃO}

O processo em favor da inclusão nas instituições de educação é mundial, vários países trabalham na perspectiva da construção de um sistema educacional inclusivo que condena qualquer forma de segregação e exclusão. No Brasil, atualmente tem organizado a modalidade de Ensino da Educação Especial a partir da perspectiva da Educação Inclusiva, em que uma das finalidades da política é a escolarização dos sujeitos considerados púbico alvo da Educação Especial que deve ocorrer no ensino comum. Entretanto, a formação inicial dos professores é insuficiente para que possam ensinar alunos com necessidade educacionais especiais. D’Ambrosio (2016, p. 14), aponta que “a matemática desenvolve o raciocínio, garante uma forma de pensamento, possibilita a criação de ideias e favorece a interdisciplinaridade".

Gerdes (2005) destaca a importância da construção do conceito matemático fundamental para o desenvolvimento da aprendizagem nas diversas áreas do conhecimento. Dessa forma, o conhecimento matemático é um processo onde fazem parte à imaginação, as conjecturas, as críticas, os erros e os acertos, direcionando quase exclusivamente no campo dos conceitos abstratos e de suas inter-relações. Assim, diante sua importância, o Ensino de Matemática de acordo com os princípios destacados nos direcionam que não deve ser elitizado para grupos de alunos que apresentam certas habilidades para a sua compreensão, mas que seja apresentada aos estudantes de tal forma que a apropriação de seu conhecimento esteja ao alcance de todos, sem distinção de sexo, idade, cor, religião, aluno indígena, com necessidades educacionais especiais, refugiado.

A partir destas observações despertou o interesse pela pesquisa na modalidade da educação especial, entretanto a escolha de uma deficiência foi fundamental para que pudéssemos desenvolver nossa pesquisa, na qual direcionamos nosso trabalho para a deficiência visual, Diante disso, procuramos nos questionar quais as barreiras pedagógicas existentes no processo de ensino e aprendizagem em matemática em uma turma do ensino fundamental em que se encontra matriculada uma pessoa com deficiência visual?

Desta forma, as expectativas e intensões da pesquisa são de contribuir para aprendizagem em matemática de alunos com deficiência visual, bem como analisar suas dificuldades no processo de ensino e aprendizagem em matemática a partir das práticas metodológicas inseridas por uma professora de matemática, identificando durante o processo as dificuldades encontradas pela docente de tornar a aluna com autonomia durante seu processo de escolarização. Nessa perspectiva Silva (2015, p. 63), destaca que: 
Este progresso didático pode acarretar a ampliação da autonomia do aluno e a aproximação de sua realidade com a matemática. Isto é, as melhoras obtidas com o ensino apontam para uma matemática que propicie a leitura do mundo e o pensamento autônomo, o que significa contribuir para o exercício pleno da cidadania.

Assim, percebemos a importância da investigação das dificuldades apresentadas pela professora de matemática e aluna com deficiência visual durante o processo de ensino e aprendizagem, pois, desta forma nos permite delinear caminhos para elaboração de sugestões para inclusão de alunos cegos nas aulas de matemática. Tornar acessível o conhecimento matemático ao aluno com necessidades educativas especiais é uma questão que preocupa o professor à medida que o aluno avança nas séries escolares. É difícil guardar informações numéricas na memória, assim como é complicado realizar cálculos mentais sem marcar as operações no papel. De fato, sem recursos especiais, alunos com cegueira terão bastante dificuldade de acompanhar a matéria (REALY, 2004).

Nesta perspectiva podemos apontar a necessidade de instrumento didático específico que possa auxiliar o aluno com deficiência visual com a finalidade de torná-lo com maior autonomia no seu processo de aprendizagem, entretanto é necessário formação ao professor de matemática que permita aquisição de conhecimento sobre as necessidades educacionais do aluno referente ao conteúdo de matemática que está sendo exposto durante as aulas.

Para Silva e Pinto (2010), além da inadequação das escolas para receberem seus discentes com deficiência e o despreparo dos professores na sua formação, as instituições de educação não possuem infraestrutura física nem materiais adequados para que os estudantes desenvolvam suas habilidades e competências.

Regiani e Mól (2013) destacam que o ensino inclusivo em nenhum momento deve ocorrer em um aspecto filantrópico e assistencialista e aponta como função das instituições educacionais apresentar com clareza as contradições sociais e propor alternativas pedagógicas com uma perspectiva inclusiva.

Moraes (2016) destaca que o deficiente visual é apontado do ponto de vista clínico, posteriormente ocorre a inserção no campo educacional, em que cabe ao professor de matemática conhecer suas necessidades educacionais especiais para que de tal forma, possam aplicar materiais didáticos específicos de acordo com o conteúdo que está sendo exposto. Caso contrário podemos nos reportar no processo histórico da pessoa com deficiência que eram excluídas e posteriormente segregadas do sistema educacional.

Sales (2013) aponta a necessidade da formação continuada de professores de matemática direcionada ao atendimento dos alunos pertencentes ao publico alvo da modalidade 
de educação especial. Nessa linha de pensamento podemos perceber a importância na formação de professores direcionada ao ensino de pessoas com necessidades educacionais tendo como finalidade torna o aluno com maior autonomia para a sua aprendizagem.

Pais (2005) direciona a abordagem presente na educação matemática como direcionamento didático para serem aplicados nas aulas de matemática para pessoas com deficiência. E dessa forma, elaborar uma proposta metodológica que possa contribuir com o processo de ensino e aprendizagem em uma perspectiva de uma matemática inclusiva.

\section{MATERIAIS E MÉTODOS}

A pesquisa foi realizada foi realizada em uma escola municipal na cidade de Manaus em uma turma do $6^{\circ}$ ano B do turno matutino no ano de 2018. Nesta turma, encontrava-se regularmente matriculado quarenta alunos com a faixa etária de 11 a 13 anos, entre os discentes uma aluna com deficiência visual congênita.

Podemos destacar como ponto fundamental para a escolha desta instituição a questão da receptividade da escola, por está aberta a proposta do objeto de estudo, autorizando a execução da pesquisa, por parte do seu gestor, além do interesse apresentado pela pedagoga da escola, professora de matemática do $6^{\circ}$ ano e demais professores da aluna deficiente visual. Desta forma, encontramos bastante segurança, disponibilidade e interesse por parte do corpo docente da escola em discutir e levantar questões e realizar intervenções de nossa parte para o desenvolvimento da pesquisa no sentido de pensar, refletir e proporcionar elementos capazes de contribuir com o processo de ensino e aprendizagem em matemática em uma escola inclusiva.

Os participantes da pesquisa foram uma professora de matemática do $6^{\circ}$ ano $\mathrm{B}$ e aluna com cegueira congênita, em que na busca de compreender os fenômenos que rodeiam o processo de ensino e aprendizagem em matemática em um contexto inclusivo, procuramos analisar as dificuldades encontradas pela professora e aluna durante as aulas de matemática.

Os participantes da pesquisa assinaram o Termo de Consentimento Livre Esclarecido, e terão suas identidades preservadas durante toda a execução da pesquisa, assim foram nomeados pelos seguintes termos: I - Professora Beta para indicar a docente que atua como titular da disciplina Matemática na turma pesquisada II - Aluna Alfa para indicar a aluna com deficiência visual.

Durante a pesquisa foram utilizadas 20 aulas referente ao planejamento da professora de matemática os quais contavam os conteúdos de operações com números naturais, potência e 
raiz quadrada. Destacamos que em nenhum momento da pesquisa utilizamos tempos de outras disciplinas para a produção de dados.

Para a coleta de dados aplicamos como técnica de pesquisa uma entrevista semiestruturada para Aluna Alfa e Professora Beta, além de aplicarmos a observação participante durante as atividades desenvolvidas nas aulas de matemática, na qual elaboramos um roteiro de observação, a fim de identificarmos os fenômenos relacionados ao objetivo da pesquisa.

A aplicação da entrevista foi em dias distintos em horário combinado com as participantes da pesquisa. Dessa forma, a dinâmica do processo de investigação pode fornecer elementos essenciais para que através da produção de dados pudéssemos analisar as informações coletadas.

Para esta pesquisa diante a busca para coleta de dados em um contexto natural que é a sala de aula e uma complexa interpretação dos fenômenos envolvendo o processo de ensino e aprendizagem, definimos por uma abordagem qualitativa.

Para Creswell (2014), concebe a pesquisa qualitativa em uma perspectiva muito ampla de estruturas interpretativas e teóricas que informam o estudo dos problemas da pesquisa, abordando os significados que os indivíduos ou grupo atribuem a um problema social ou humano. Ele destaca o fato de que os pesquisadores nessa abordagem realizam a coleta de dados em um contexto natural, sendo o local de nossa pesquisa a sala de aula em uma instituição de educação.

Com relação à análise dos dados Creswell (2014) destaca que podem ser realizadas tanto de forma indutiva quanto dedutiva, e aponta alguns pontos importantes para o desenvolvimento da pesquisa qualitativa como incluir as vozes do participante, deixar claro a reflexão do pesquisador, descrição complexa e interpretação do problema e deixar claro de forma bem clara a contribuição da pesquisa para a literatura e que mudança ela pode proporcionar a sociedade.

Nestes direcionamentos apontados pelo autor, percebemos que a abordagem qualitativa permite uma análise com variedade de técnicas no sentido de entender e interpretar um determinado objeto de estudo, fato que enriquece a análise dos fenômenos abordados na pesquisa relacionados ao processo de ensino e aprendizagem em uma perspectiva inclusiva.

De acordo com Moreira (2011), o investigador interpretativo observa atentamente de dentro do ambiente estudado, onde os fenômenos de interesse na educação podem ser relacionados em cinco, são eles: professor (ensino), aluno (aprendizagem), currículo, avaliação e contexto. Na pesquisa a qual estamos realizando temos como objeto de estudo o ensino e 
aprendizagem, entretanto compreendemos a ligação entre os fenômenos que podem ocorrer durante o processo de observação durante as aulas de matemática.

\section{RESULTADOS E DISCUSSÕES}

Este item tem como objetivo apresentar os dados produzidos durante a pesquisa de campo. Para isso, utilizamos informações dos momentos observados nas aulas de matemática do $6^{\circ}$ Ano B, diário de campo do professor pesquisador, as transcrições dos áudios e entrevistas realizadas com os participantes da pesquisa. Dessa forma, procuramos descrever nossas análises através dos diálogos com a literatura pertinente com o intuito de entendermos a problemática investigada e de alguma forma, através da concepção filosófica da dialética, propor mudanças no contexto educacional em uma perspectiva inclusiva.

\subsection{O ensino em matemática em uma perspectiva inclusiva}

No decorrer das nossas observações nas aulas de matemática, percebemos a preocupação da educadora na aprendizagem de seus alunos, em especial para estudante com deficiência visual, pois em todas as aulas posteriormente as explicações dos conteúdos e propostas de atividade para a turma, a Professora Beta se dirigia a aluna, e de forma individual procurava passar mais informações para a sua compreensão. Nesse procedimento adotado, notamos uma exposição de aula em duas etapas, uma explicação geral para todos os alunos e outra específica para aluna cega, fato este que exigia da docente um trabalho dobrado.

Os procedimentos metodológicos adotados pela Professora Beta consistiam em aulas expositivas com a utilização do livro didático, apagador, pincel e quadro branco, em nenhum momento foi utilizado algum tipo material específico para aprendizagem de uma aluna cega. Nessa perspectiva, Gellert (2004) assinala que o material didático é um mediador entre a intenção do ensino e os resultados obtidos pelos alunos, dessa forma, concordamos com o autor, pois em vários momentos verificamos a necessidade de um material didático que auxiliasse a Aluna Alfa para compreensão dos conteúdos que estavam sendo exposto e ao mesmo termo fornecer a discente uma autonomia no processo de aprendizagem.

A Professora Beta demonstrou não ter conhecimento sobre recursos didáticos que poderiam ser utilizados para aprendizagem de alunos com deficiência visual como soroban, multiplano, material dourado, pois em nenhum momento orientou a aluna a utilizar algum material didático com o qual pudesse ser um mediador no processo de ensino e aprendizagem. 
Nessa linha de pensamento concordamos com Sales (2013) quando afirma que "o processo de inclusão deve garantir que os alunos com deficiência participem da comunidade de aprendizagem, além de promover um real avanço nas habilidades cognitivas de socialização", porém algumas pesquisas mostram que nas escolas de ensino regular, determinadas práticas pedagógicas não são suficientes para aprendizagem de inúmeros alunos com deficiência, os quais necessitam de métodos de ensino diferenciados e de adaptação curricular para promover seu desenvolvimento e aprendizado e nesta pesquisa evidenciamos a falta de conhecimento de prática que podem contribuir com o processo de ensino e aprendizagem de alunos com deficiência visual.

Uma estratégia frequentemente adotada pela educadora nas explicações dos conteúdos e propostas de atividades para a turma do $6^{\circ}$ ano $\mathrm{B}$ consistia em posicionar em forma de rodizio um discente ao lado da estudante cega para que a mesma pudesse acompanhar as explicações e os exercícios propostos nas aulas de matemática, entretanto, verificamos que nem sempre os estudantes se disponibilizavam para a função, pois se preocupavam com suas anotações particulares e finalização de suas atividades para entregar a professora, e nessas situações a Aluna Alfa nas aulas de matemática deixava de fazer suas anotações e por muitas vezes não apresentava os exercícios propostos pela professora.

Diante disso, notamos a necessidade de uma formação para professores em que a proposta curricular do curso de matemática possa contemplar práticas metodológicas direcionadas as necessidades dos estudantes público alvo da Educação Especial, pois concordamos com Silva e Pinto (2010), que destacam o despreparo dos professores na sua formação e que as escolas estão inadequadas para receberem seus discentes com deficiência e, por não possuírem infraestrutura física nem materiais adequados para que os estudantes possam desenvolver suas habilidades e competências.

Nas observações realizadas com o discente posicionado ao lado da Aluna Alfa, verificamos que os registros da estudante cega eram feitos no sistema de código e leitura em Braille, entretanto notamos que a professora de matemática não tinha nenhum conhecimento deste código, o que impossibilitava a verificação de suas anotações particulares da discente e consequentemente a correção de suas atividades. Fato este poderia ser evitado caso a formação do professor para o ensino de matemática contemplasse em sua proposta curricular práticas para o ensino de pessoas com necessidades educacionais especiais.

Neste contexto, podemos enfatizar que a formação continuada para professores de matemática poderia amenizar essas dificuldades encontradas pelos docentes, entretanto, a formação continuada propostas pelas secretarias estaduais e municipais não contemplam de 
forma eficaz formação para que os professores de matemática possam aplicar nas salas que vivenciam o processo de inclusão.

Com relação à avaliação a Professora Beta apresentou imensas dificuldades em avaliar a aluna cega. No dia da avaliação escrita ela convidou a mãe para sentar ao lado da aluna, para que realizasse a leitura das dez questões propostas da prova, e dessa forma a aluna registrava as respostas em Braille. A professora regente entregou uma prova para o pesquisador, onde de acordo com a estratégia aplicada de posicionar a mãe ao lado da aluna, verificamos a necessidade de adaptações na avaliação, como as questões 6 e 8 conforme mostra a figura 1 , pois ambas fornecem, através da leitura, a reposta imediata para aluna. A correção desta avaliação ocorreu em outro momento, através da leitura da aluna cega no registro realizado em sua prova.

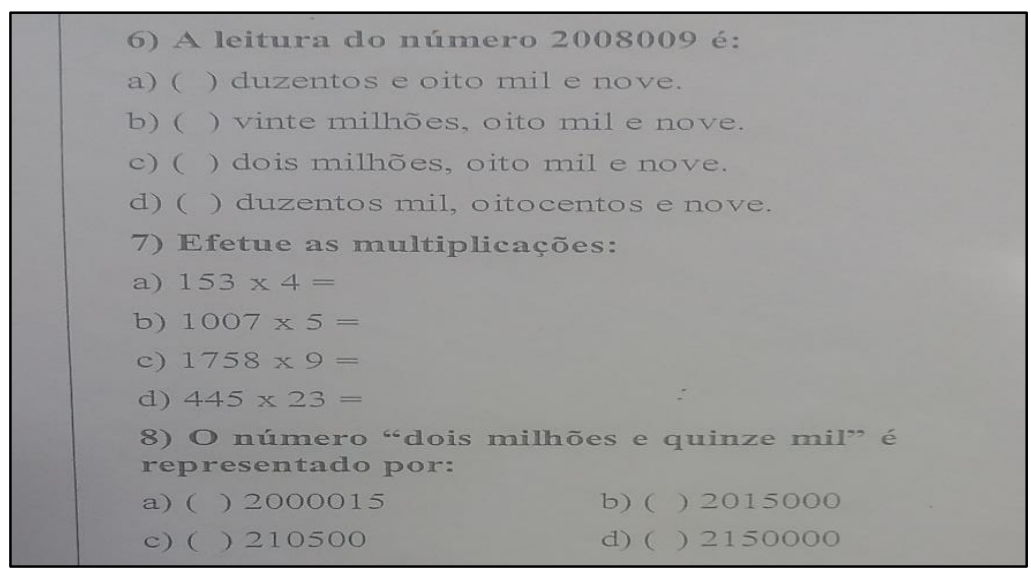

Figura 1: Avaliação de matemática. Fonte: Rodrigues (2018).

Nesta situação, a Professora Beta poderia optar por elaborar as questões em um software como o DosVox ou solicitar um auxílio das professoras da sala de recurso multifuncional da escola.

A interação com os alunos da turma do $6^{\circ}$ ano B ocorriam frequentemente durante as aulas através de questionamentos realizados pela Professora Beta de acordo com o conteúdo exposto, onde a aluna deficiente visual era sempre acionada nas perguntas, e suas respostas eram sempre satisfatórias. Mas a interação entre a turma ocorreu de forma intensa em uma atividade em grupo realizada em uma sexta-feira. Neste dia a professora levou para a sala um jogo relacionado ao conteúdo de múltiplos e divisores, entretanto o material apresentado não contemplava a Aluna Alfa, com isso, a discente precisou de auxílio para participar da atividade em grupo. 


\subsection{Aprendizagem em matemática em uma perspectiva inclusiva}

Nas aulas de matemática notamos que a Aluna Alfa, ouvia atentamente as explicações da Professora Beta para que de tal forma pudesse assimilar os conteúdos exposto durante as aulas de matemática. Isso ficou bem evidente quando perguntamos para a discente: "Como você assimila os conteúdos de matemática que a professora explica nas aulas de matemática?” Ela respondeu: "Prestando atenção quando ela ler ou fala eu presto atenção, pra eu poder gravar tudo na minha mente pra depois fazer prova ou exercício ou alguma coisa”. Na fala da discente fica evidente a limitação no procedimento adotado para uma aprendizagem dos conceitos matemáticos, na sua condição de deficiente visual é necessário propiciar mecanismos e metodologias que lhe possam auxiliar melhor no aprendizado da matemática.

Assim, concordamos com Kastrup (2007), quando destaca a importância dos estímulos e recursos adequados que devem ser aplicados nas pessoas com deficiência visual, pois estes podem desenvolver uma reorganização do sistema cognitivo possibilitando orientar a percepção de signos não visuais direcionando para uma aprendizagem por meio de outros sentidos. E, apenas ouvindo a Professora Beta foi insuficiente para a discente a aprendizagem dos conceitos matemáticos.

No momento em que a educadora utilizava o quadro branco, pincel ou livro didático de matemática para passar alguma atividade ou explicar determinado assunto, era um momento em que acentuava a dificuldade da aluna cega para a compreensão do assunto. Destacamos que o livro didático disponibilizado pela escola era em tinta e sem adaptações, o que não contempla as necessidades de uma estudante cega, em que o ideal seria um livro com o código de leitura e escrita em Braille, pois a discente apresentou um amplo domínio durante nossa pesquisa.

A estratégia utilizada pela Professora Beta com o intuito de colaborar com a aprendizagem da aluna deficiente visual era posicionar em forma de rodizio um aluno não deficiente para ajudá-la nas anotações e realizações de suas atividades. Diante a estratégia tínhamos dúvidas relacionadas à eficiência do procedimento então questionamos a Aluna Alfa: "Quais as contribuições dos alunos que ficam ao seu lado durante as aulas de matemática? Eles ajudam nas suas anotações e atividades?” Ela respondeu: “O meu colega do lado ajuda um pouco, ele só fala o que tá escrito, ajuda a fazer a tarefa quando as vezes a professora coloca desenho, igual as outras matérias, mas na de arte é o professor que explica pra mim o que ele desenhou". 
Notamos na fala da discente que a estratégia em posicionar um aluno da turma ao lado pode ter suas contribuições, entretanto no fragmento de sua fala "[...] mas na de arte é o professor que explica pra mim o que ele desenhou", penso que o aluno possa não está preparado para desempenhar essa função, pois na imagem podem conter informações em que apenas o professor possa estar habilitado a fazer uma áudio descrição para aluna. Em algumas aulas notamos a aluna estática, sem fazer a atividade e quando questionada relacionada a isso disse o seguinte: "Nem sempre consigo fazer as atividades, porque às vezes não tem ninguém para ditar pra mim, às vezes ninguém quer, aí não dá tempo e levo para casa a atividade e a minha mãe dita”. Portanto, nem sempre os alunos da turma estão disponíveis para colaborar com a discente cega, pois precisam fazer suas tarefas no tempo disponibilizado da aula.

Conforme já relatamos anteriormente a Aluna Alfa tinha amplo conhecimento sobre a leitura e escrita em Braille, pois suas anotações particulares das aulas e as atividades realizadas eram registradas no referido código. Entretanto, nas aulas de potências e radicais, conseguimos notar a falta de conhecimento sobre o sistema Braille relacionado aos símbolos de matemática, pois a cada conteúdo novo apareciam símbolos em que a discente não sabia como registrar. Em uma dessas situações o estudante posicionado ao seu lado realizou o registro em tinta na folha juntamente com o código Braille conforme mostra a figura 2.

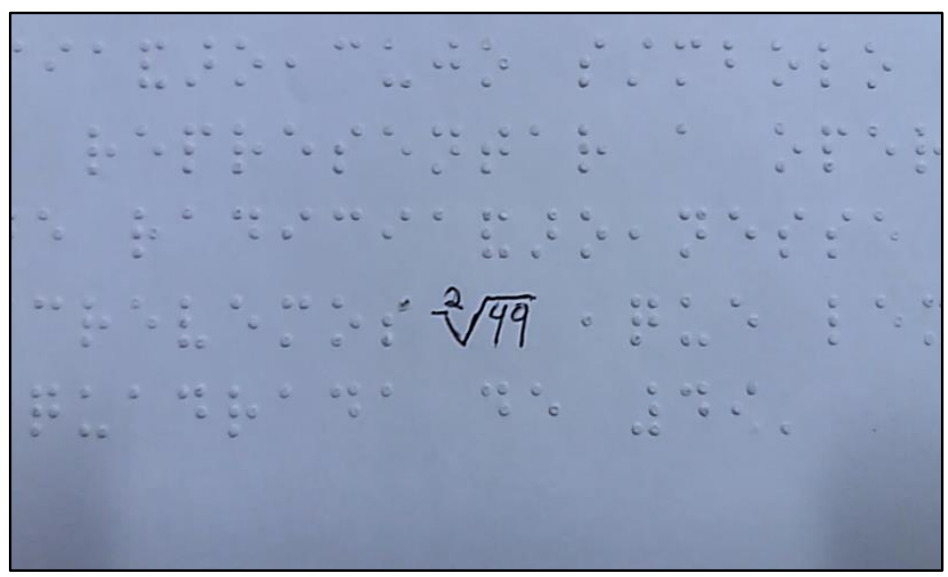

Figura 2: Escrita em tinta pelo aluno.

Fonte: Rodrigues (2018).

Diante a ausência de conhecimento por parte da aluna do código unificado de matemática para o sistema Braille perguntamos durante o atendimento: "Você conhece os símbolos de matemática em Braille?” Ela respondeu: "Não, eu é só uma parte que não tinha esses sinais lá pro meio da aula, aí quando eu não sei fazer o símbolo eu peço para a minha colega fazer em tinta mesmo, na folha (...) não sei aspas, parênteses um monte de coisas, aquele negócio três elevado ao quadrado ao cubo". No momento surgiu outra dúvida e aluna foi 
questionada: "E quando o aluno ao seu lado não registra em tinta o que você faz?". A discente respondeu: "eu escrevo em Braille raiz, parênteses, dois elevado ao quadrado". Podemos evidenciar a fala da aluna no registro da figura 3.

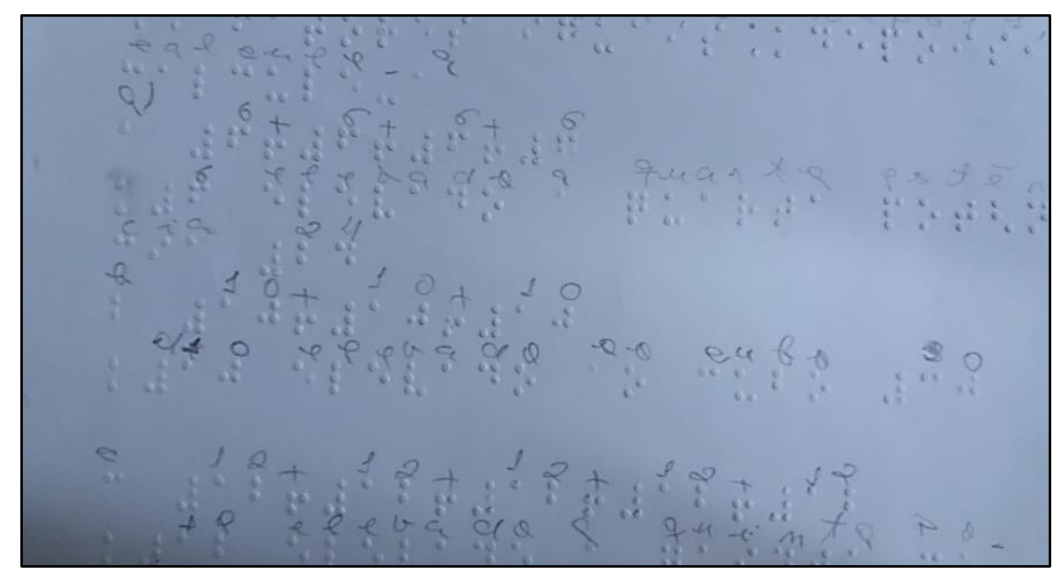

Figura 3: Atividade sobre potências. Fonte: Rodrigues (2018).

Com relação aos instrumentos didáticos específicos para auxiliar na aprendizagem da discente deficiente visual nas aulas de matemática, presenciamos apenas a utilização de uma reglete, punção, em que ambas ferramentas são suporte para a escrita em Braille. Diante os fatos observados, evidenciamos a necessidade da busca de outros recursos de acessibilidade que possam contribuir com o processo de ensino e aprendizagem de matemática em uma perspectiva inclusiva.

\section{CONSIDERAÇÕES}

Considerando o objetivo de nossa pesquisa o qual foi analisar o processo de ensino e aprendizagem em matemática as dificuldades encontradas por uma aluna com deficiência visual a partir das práticas metodológicas inseridas por uma professora de matemática. Podemos verificar durante a pesquisa algumas barreiras pedagógicas ocasionadas diante das práticas metodológicas aplicadas durante o processo.

Neste trabalho, percebemos algumas dificuldades encontradas pela professora de matemática em ensinar uma aluna com deficiência visual ocasionada por uma lacuna no seu processo de formação que em nenhum momento de sua graduação a proposta curricular apresentou direcionamentos pedagógicos para contribuir com o ensino para pessoas com necessidades educacionais especiais. 
Com relação a discente, notamos uma ausência no seu processo formativo referente ao auxílio de matérias pedagógicos específicos para pessoas com deficiência visual, como o soroban e software DosVox, bem como uma oferta por parte das secretarias estaduais e municipais de educação referente ao Atendimento Educacional Especializado garantindo por lei para os alunos pertencentes a modalidade de Educação Especial.

Diante o exposto, consideramos que na formação do professor de matemática é necessário inserir práticas pedagógicas que auxiliem o educador ferramentas direcionadas ao ensino de matemática para pessoas com necessidades educacionais especiais, o qual ficou evidente durante a pesquisa e aplicação de materiais didáticos direcionados para uma aluna cega. Entretanto, verificamos a importância por parte das instituições educacionais a oferta de serviços complementares que auxiliem no processo de escolarização das pessoas com deficiência visual.

Portanto, o contexto escolar inclusivo, vivenciado pelos discentes com deficiência visual e professores de matemática, aponta por necessidades de mudanças nas estruturas de currículos dos cursos de licenciatura em matemática. Além disso, apontam para a necessidade de pesquisas direcionadas a materiais que possam contemplar alunos com deficiência e os demais alunos no processo de ensino e aprendizagem em matemática.

\section{REFERÊNCIAS}

CRESWELL, J. W. Investigação qualitativa e projeto de pesquisa: escolhendo entre cinco abordagens. 3. ed. Porto Alegre: Penso, 2014.

D’AMBRÓSIO, U. Etnomatemática: arte ou técnica de explicar e conhecer. $8^{\text {a }}$. ed. São Paulo: Ática, 2016.

GERDES, P. Sobre o despertar do pensamento geométrico. Editora da UFPR, Curitiba, 2005.

GELLERT, U. Didactic material confronted with the concept of mathematical literacy. Educational Studies in Mathematics, 55, 163-179. 2004

KASTRUP, V. A invenção na ponta dos dedos: a reversão da atenção em pessoas com deficiência visual. Psicologia em Revista, Belo Horizonte, v. 13, n.1, p. 69-93, jun, 2007.

MORAES, M. E. L. A leitura tátil e os efeitos da desbrailização em aulas de matemática. 2016. 318f. Dissertação (Mestrado em Educação em Ciências e Matemática) - Universidade Federal do Pará, 2016.

MOREIRA, M. A. Metodologias de pesquisa em ensino. São Paulo: Editora Livraria da Física, 2011. 
PAIS, L.C. Educação Matemática: uma introdução. São Paulo: EDUC- PUC-SP, 2005.

REALY, L. Escola Inclusiva: Linguagem e mediação. Campinas: Editora Papirus, 2004.

REGIANI, Anelise Maria; MÓL, Gerson de Souza. Inclusão de uma aluna cega em um curso de licenciatura em química. Revista Ciência e Educação. v.19, n.1. pg 123-134. 2013.

SALES, E. R. A visualização no ensino de matemática: uma experiência com alunos surdos. 2013. 235 f. Tese (Doutorado em Educação Matemática) - Programa de PósGraduação em Educação Matemática, Universidade Estadual Paulista, Rio Claro, 2013.

SILVA, L. M. S. Do improviso às possibilidades de ensino: estudo de caso de uma professora de matemática no contexto da inclusão de estudantes cegos. 2015. 199f. Tese (Doutorado em Educação Matemática) - Universidade Estadual Paulista "Júlio de Mesquita Filho", UNESP, 2015.

SILVA, M. C. R. F.; PINTO, T. C. L. Inclusão social: o design como parte integrante no ensino da arte. Florianópolis, v. 02, jan./dez. 2010.

Submetido em: 09 de agosto de 2019. Aprovado em: 20 de dezembro de 2019. 